\title{
Zwei Schwesternhandschriften vereint
}

\section{Erwerbung eines Turnierbuchs der Freiherrlichen Familie von Gemmingen}

Turnier Buch. Zusamen geordnete Turnier, Teutscher Adelicher Nation [...] mit iren Jarzalen, vnd namen, sonderlich des Vhralten Edlen Rittermessigen stammen Gemmingen, mitt iren wappen, vnd besuchten orten der außgeschribenen Turniren / Im iar 1615

Deutsche Handschrift, Papier, 1615

Umfang: 59 Blätter; Format: $37 \times 19 \mathrm{~cm}$

Brauner Kalbledereinband über Pappe mit Einzelstempeln (Mauresken, Doppellilien) und zwei Rollen (Salvatorrolle; Kopf-Blattwerk-Rolle). Geprägte Angabe zum Bindejahr (1618) sowie Buchstabensupralibros "FVGZF" (Friedrich von Gemmingen zu Fürfeld) und "ASVGGGVK" (Anna Sibylla von Gemmingen geborene Greck von Kochendorf).

Cod. hist. fol. 298a

Bis heute prägt das Bild vom wappenbehängten, geharnischten Ritter, der hoch zu Ross mit gezückter Lanze auf seinen Gegner zureitet, unsere Vorstellung vom Mittelalter. Turniere, auf denen edle Recken um die Gunst einer hohen Dame buhlen, farbenfrohes Gepränge mit diversen Lustbarkeiten am Rande der Szenerie sind unverzichtbare Bestandteile dieses Bildes. Dieser nostalgisch-verklärende Blick auf eine vergangene Zeit ist nicht nur ein Phänomen unserer Gegenwart: Das hochmittelalterliche Rittertum wurde obsolet, als spätestens seit dem 15. Jahrhundert der Einsatz von Feuerwaffen sowie das Aufkommen von Söldnerheeren das Kriegswesen von Grund auf revolutionierten. Dennoch standen im 16. und beginnenden 17. Jahrhundert festliche Turnierveranstaltungen zur Repräsentation von Macht und Reichtum bei Fürsten und Adeligen hoch im Kurs. Zugelassen waren nur hochstehende und besonders würdige Persönlichkeiten, über deren "Turnierfähigkeit" nach einem umfangreichen Regelwerk entschieden wurde. Man könnte überspitzt sagen: Nur der Adel konnte an den Turnieren teilnehmen, gleichzeitig adelte aber auch die Teilnahme in ganz besonderer Weise. So verwundert es nicht, dass Adelsgeschlechter ein Interesse daran hatten,

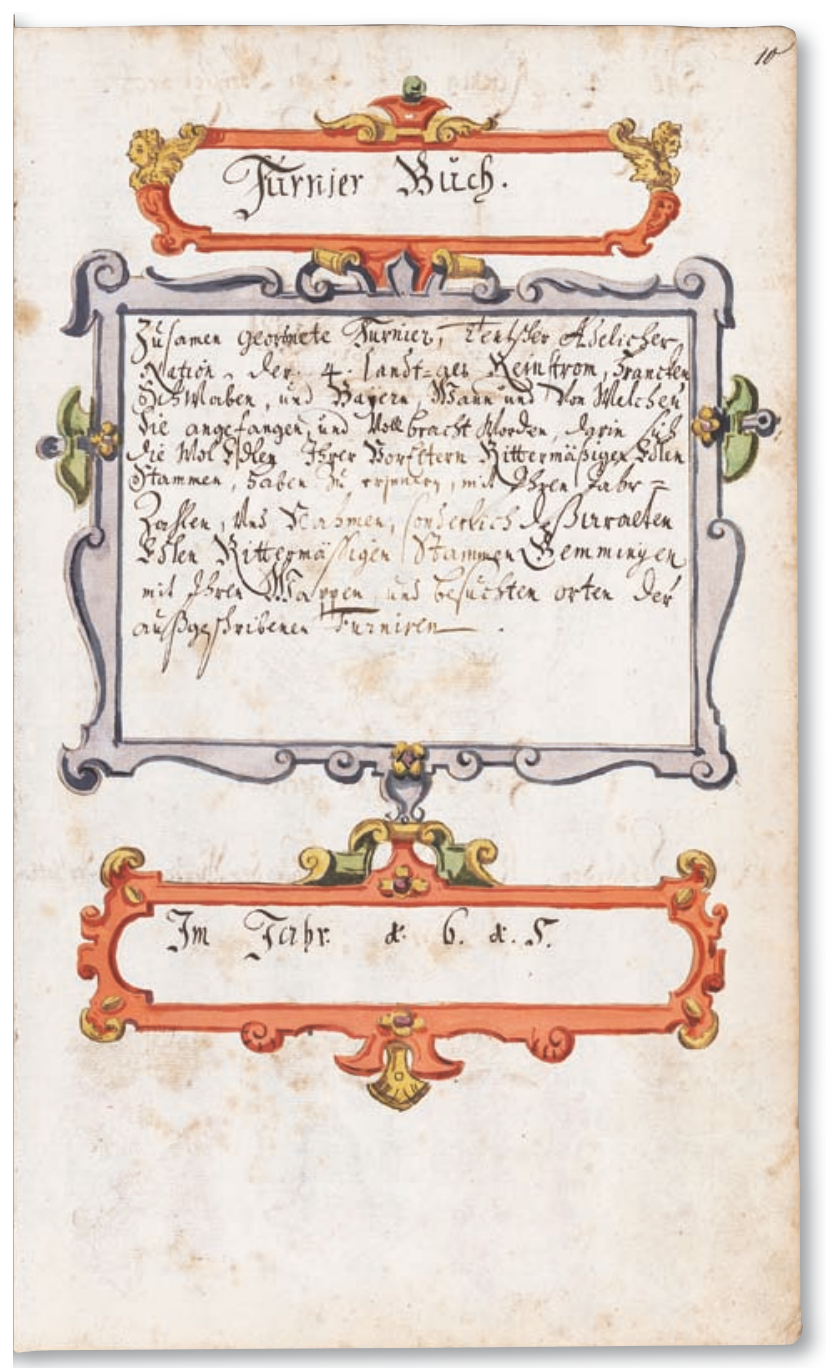

Cod. hist. fol. 298 10r

die Namen ihrer Mitglieder in sogenannten Turnierbüchern verewigt zu finden. Ein namentlich nicht bekannter Wappenmaler fertigte zu Beginn des 17. Jahrhunderts auf der Grundlage eines Druckes, des seit seinem ersten Erscheinen im Jahr 1530 sehr verbreiteten Turnierbuchs von Georg Rüxner, gleich mehrere individualisierbare Exemplare in Serie an. Die mit Wappen, Turnierszenen und Herrscherfiguren farbenprächtig geschmückten Handschriften konnten dann auf konkrete Abnehmer individuell zugeschnitten werden. Bekannt sind heute insgesamt sieben Exemplare. Angefertigt wurden sie für zwei Adelsfamilien der Kraichgauer Ritterschaft - die von Helmstatt und die von Gemmingen - sowie für eine Einzelperson, einen Deutschordenskomtur in 
Heilbronn mit Namen Carl von Wolckenstein. Zwei Handschriften entfallen auf die Familie von Helmstatt und insgesamt vier auf Angehörige derer von Gemmingen. Im Besitz der Württembergischen Landesbibliothek befinden sich nun seit kurzem zwei der Exemplare, die für die Familie von Gemmingen ausgestattet wurden. Vielleicht schon zum Gründungsbestand oder doch zumindest zu den frühen Erwerbungen des Hauses gehört die Handschrift mit der Signatur Cod. hist. $2^{\circ} 298$. Sie weist auf der Rückseite des ersten Blattes die Wappen Friedrichs von Gemmingen zu Fürfeld und seiner Gemahlin Anna Sibylla (geb. Greck von Kochendorf) auf. Es folgen großformatige, gefaltete Tafeln mit den Stammbäumen derer von Gemmingen, Landschad und Greck. Diesem Exemplar konnte im Frühjahr dieses Jahres eine "Schwesternhandschrift" zu Seite gestellt werden: Die in Berlin bei Stargardt ersteigerte Handschrift wird nun unter der Signatur Cod. hist. $2^{\circ} 298$ a verwahrt. Beide Handschriften ähneln sich natürlicherweise aufgrund ihrer Herstellungsumstände sehr, enthalten aber auch signifikante Abweichungen: So sind bei dem jüngst erstandenen Exemplar lediglich zwei Stämme mit Mitgliedern derer von Greck und von Gemmingen auf der ersten Rectoseite abgebildet, die großen Falttafeln entfallen. Dafür aber deuten die Supralibros auf dem Einband dieser Handschrift ebenfalls auf Friedrich von Gemmingen zu Fürfeld und seine Frau Anna Sibylla hin. Insgesamt ist der Zustand der neu erworbenen Handschrift gut, die Farben heute noch strahlend, das Papier allerdings etwas angegriffen und durch frühere Behandlung von Rissen beeinträchtigt. Beide Handschriften stehen nun der Forschung mit der Möglichkeit zum direkten Vergleich zur Verfügung.

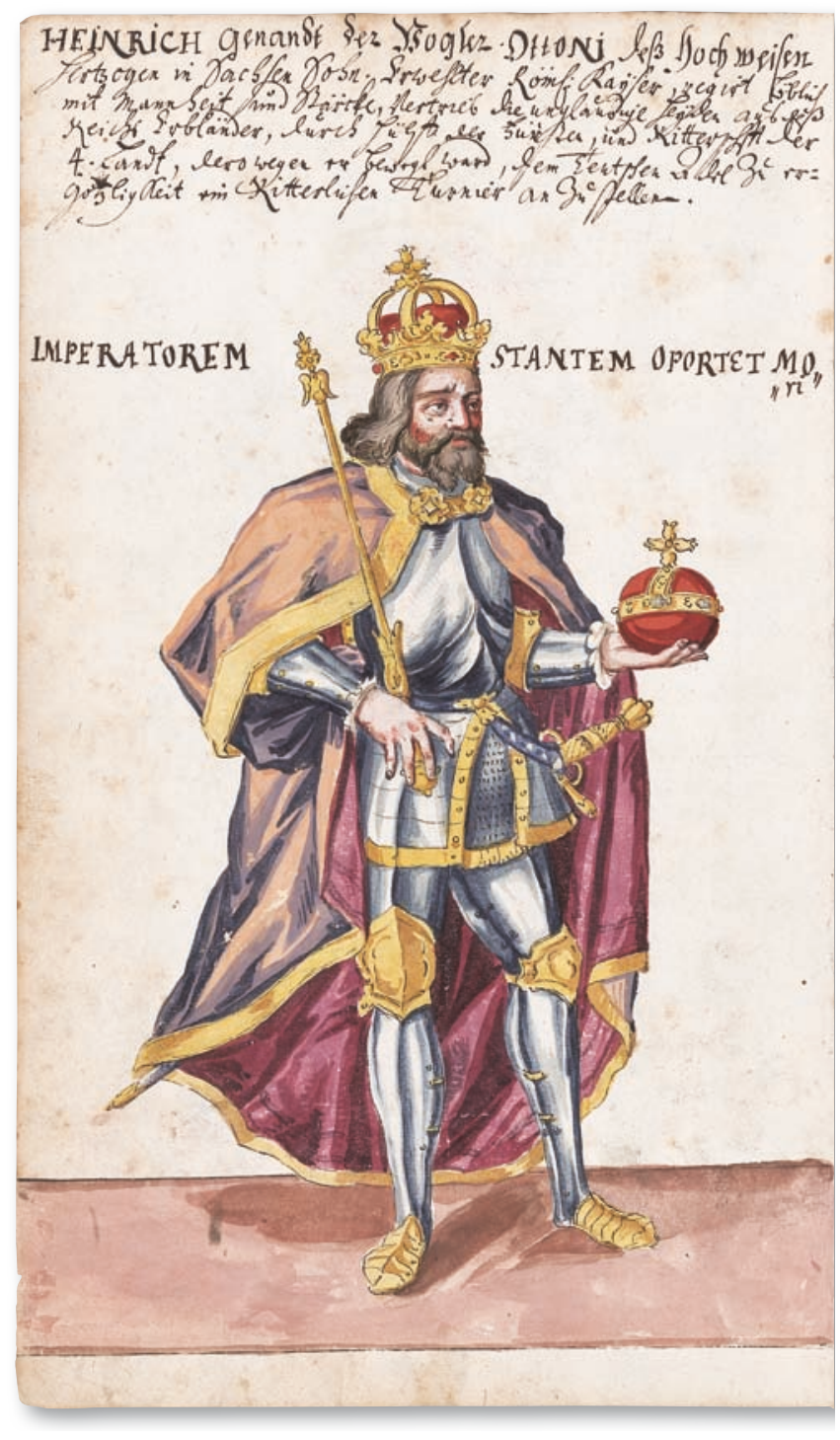

Cod. hist. fol. $29815 \mathrm{v}$

Lit.: Kurras, Lotte: Turnierbuch aus der Kraichgauer Ritterschaft. Kommentar zur Faksimileausgabe des Cod. Ross. 711. Zürich 1983.

Mein Dank gilt Frau Ulrike Marburger für die Begutachtung der Einbandstempel. 